\title{
Robert James Furlong McInerney
}

\author{
AM, CMG, KCSG, KM, MBBS, FRCS, FRACS, FACS, FRCOG, FRACOG
}

Robert (Bob) McInerney was a distinguished obstetrician, gynaecologist and sports doctor. He was born on 22 August 1918 in Haberfield, New South Wales, and educated at De La Salle College Ashfield, where he was dux in 1936. He won a scholarship to the University of Sydney to study medicine, and graduated in 1942, coming third in his year and receiving the Robert Craig Prize in Surgery.

During World War II, he served in New Guinea and Borneo as a medical officer with the 2/43 Infantry Battalion. On his return to Sydney, he worked at St Margaret's Hospital as a medical superintendent and at St Vincent's Hospital as assistant gynaecologist. He also spent time in England, where he worked at St Thomas' Hospital in London and attained Fellowship of the Royal College of Surgeons.

In 1952, Bob commenced his Macquarie Street practice and married Betty Stormon. He also began his long association with the Western Suburbs Magpies Rugby League Football Club, where he was the club doctor until 1983.
He was a Fellow of the Royal College of Obstetricians and Gynaecologists, a member of the Executive Council of the International Federation of Gynaecology and Obstetrics, Chairman of the NSW State Committee of the Royal Australian College of Obstetricians and Gynaecologists, a member of the NSW Medical Board and a Master of the Medical Guild of St Luke.

In 1964, at St Vincent's, he was the first Australian obstetrician to successfully perform an intrauterine blood transfusion.

His medical achievements were recognised in 1989, when he was made a Member of the Order of Australia.

In retirement, Bob lived an active life that included helping people addicted to alcohol and drugs in the Darlinghurst area, and he was a generous benefactor to a number of charities.

He developed ischaemic heart disease and congestive cardiac failure and died on 23 May 2014.

James B Roche doi: 10.5694/mja14.01314 